\title{
Following the results of the EMPA-REG OUTCOME trial with empagliflozin, is it possible to speak of a class effect?
}

This article was published in the following Dove Press journal:

International Journal of General Medicine

13 January 2017

Number of times this article has been viewed

Francisco Javier

Ampudia-Blasco'

Irene Romera ${ }^{2}$

Bernat Ariño ${ }^{3}$

Ramón Gomis ${ }^{4}$

'Endocrinology and Nutrition Department, Clinic University Hospital Valencia, Valencia, Spain; ${ }^{2}$ Eli Lilly and Company España, Madrid, Spain; ${ }^{3}$ Boehringer Ingelheim España, Barcelona, Spain; ${ }^{4}$ Endocrinology Department, Hospital Clinic Barcelona, Barcelona, Spain
Correspondence: Francisco Javier Ampudia-Blasco

Endocrinology and Nutrition Department, Clinic University Hospital Valencia, Avenida de Blasco Ibáñez, I7, 46010 Valencia, Spain

Tel +34961973500

Email ampudia_fra@gva.es
Background: The recently published cardiovascular outcomes data for the first sodium-glucose cotransporter 2 (SGLT2) inhibitor, empagliflozin, have shown cardiovascular safety and additional benefits in patients with type 2 diabetes and established cardiovascular disease. Empagliflozin showed lower rates of death from cardiovascular causes or from any causes and lower hospitalization rates from heart failure compared with placebo, both in addition to standard care. This commentary discusses the existence of a possible class effect considering the available evidence described for other SGLT2 inhibitors.

Main text: Empagliflozin, dapagliflozin and canagliflozin share the same mechanism of action, and it is a plausible hypothesis that some of the benefits of empagliflozin treatment could also be expected from other SGLT2 inhibitors. However, the rapid and persistent occurrence of cardiovascular benefits observed with empagliflozin and the different results shown by the three inhibitors in meta-analyses of some of their respective Phase II and III trials might suggest another possible mechanism of action, perhaps related to the different selectivity to inhibit SGLT-2 and other SGLT family members that these compounds present.

Conclusion: There is still lack of evidence to answer whether the cardiovascular benefits observed with empagliflozin in the EMPA-REG OUTCOME study could be seen as a "class effect", which is also attributable to dapagliflozin and canagliflozin.

Keywords: cardiovascular, outcome studies, SGLT2 inhibitors, empagliflozin, dapagliflozin, canagliflozin

\section{Background}

Following presentation and publication of the results of the EMPA-REG OUTCOME study, ${ }^{1}$ which showed significantly lower rates of death from cardiovascular causes, death from any cause and hospitalization for heart failure with empagliflozin in patients with type 2 diabetes and established cardiovascular disease compared with placebo, both in addition to standard care, the question we must ask ourselves is whether the observed benefits could also be extended to other molecules in the same class of sodium-glucose cotransporter 2 (SGLT2) inhibitors, such as dapagliflozin or canagliflozin.

\section{Main text}

It is true that all three drugs share the same mechanism of action. They all reduce hyperglycemia by decreasing renal reabsorption of glucose and inducing an increase in glycosuria. Increased urinary excretion of glucose is associated with weight loss due to loss of glucose (for every gram excreted, $4 \mathrm{kcal}$ is lost) and a slight increase in diuresis. ${ }^{2}$ As regard the cardiovascular benefits observed with empagliflozin, it has been 
suggested that they result from multidimensional changes that are directly or indirectly related to the induced glycosuria, such as weight loss and lower blood pressure, from visceral adiposity, hyperinsulinemia, albuminuria and elevated levels of uric acid. These actions have also been observed with dapagliflozin and canagliflozin and could mean that it is a plausible hypothesis that the benefits of empagliflozin could also be expected from other SGLT2 inhibitors (a class effect). ${ }^{3}$

However, the rapid and persistent occurrence of cardiovascular benefits observed with empagliflozin indicates that it is probably not directly related to its antihyperglycemic, antihypertensive, or weight loss effects (class effect) or an effect on atherosclerosis. This leads us to consider other possible mechanisms of action (hemodynamic benefits, reduction in sympathetic tone, antialdosterone effect, reduction in oxidative stress, reduction in myocardial oxygen demand, etc.), which may or may not be intrinsic to empagliflozin. There are also differences between the three molecules in terms of their selectivity toward the glucose transporter SGLT2, although the associated clinical implications are unknown. Empagliflozin presents greater selectivity for SGLT2 versus SGLT1 (>2500-fold), followed by dapagliflozin (>1200-fold) and canagliflozin (>250-fold). Moreover, compared with SGLT6, both empagliflozin and dapagliflozin also showed more than 500-fold selectivity, whereas canagliflozin showed only 90 -fold selectivity. ${ }^{4}$

What is more important, meta-analyses based on Phase II and III studies with empagliflozin, dapagliflozin and canagliflozin show very different results..$^{5-7}$ In all of them, the primary composite outcome was observation time required until the occurrence of death from cardiovascular causes, non-fatal myocardial infarction, non-fatal stroke or hospitalization for unstable angina. In the case of empagliflozin, the hazard ratio (HR) versus placebo was 0.48 (95\% confidence interval [CI]: $0.27-0.85)$, which indicates a cardiovascular risk reduction of $-52 \% .{ }^{5}$ Comparatively, the HR with dapagliflozin was 0.82 (95\% CI: $0.58-1.15 ;-18 \%)^{6}$ and with canagliflozin was 0.91 (95\% CI: $0.68-1.22 ;-9 \%)^{7}$ These data suggest, although only preliminarily, that there is a greater reduction in cardiovascular risk with empagliflozin than with dapagliflozin or canagliflozin, although it must be interpreted with caution, as mentioned earlier.

As regard prospective studies of the long-term cardiovascular safety of SGLT2 inhibitors, we are awaiting the results of the CANagliflozin cardioVascular Assessment Study (CANVAS) $^{8}$ with canagliflozin in 2017 and the Dapagliflozin Effect on CardiovascuLAR Events (DECLARE-TIMI 58) study with dapagliflozin in 2019. One important difference between the EMPA-REG OUTCOME study and these ongoing studies is the study populations (Table 1). Whereas the patients included in the EMPA-REG OUTCOME study had established vascular disease, in the CANVAS and DECLARE-TIMI 58 studies, the patients may have established vascular disease or high cardiovascular risk. ${ }^{3}$ It is not known whether these differences could play an important part in demonstrating the cardiovascular benefits of the different drugs and in the magnitude of the effect.

If we review other therapeutic classes, highly differing results have also been found in cardiovascular safety studies between several of the drugs investigated. In the case of glitazones, rosiglitazone was withdrawn by the European Medicines Agency (EMA) due to aspects of cardiovascular safety suggested by a meta-analysis, ${ }^{9}$ while pioglitazone

Table I Cardiovascular safety studies with empagliflozin, dapagliflozin and canagliflozin in patients with type 2 diabetes mellitus

\begin{tabular}{|c|c|c|c|c|}
\hline Parameter & EMPA-REG OUTCOME' & DECLARE-TIMI 58 ${ }^{14}$ & CANVAS $^{8,15}$ & CANVAS-R $^{16}$ \\
\hline Drug & Empagliflozin & Dapagliflozin & Canagliflozin & Canagliflozin \\
\hline$n$ & 7020 & 17276 & $4327^{\circ}$ & $5826^{\circ}$ \\
\hline Primary end point & $\begin{array}{l}\text { CV death, non-fatal MI or } \\
\text { non-fatal stroke }\end{array}$ & $\begin{array}{l}\text { CV death, non-fatal MI or } \\
\text { ischemic stroke }\end{array}$ & $\begin{array}{l}\text { CV death, non-fatal MI or } \\
\text { non-fatal stroke }\end{array}$ & Progression of albuminuria \\
\hline Main inclusion criteria & $\begin{array}{l}\text { Established CV disease, } \mathrm{HbAlc} \\
\geq 7.0 \% \text { and }<9 \% \text { (patients without } \\
\text { previous hypoglycemic treatment) } \\
\text { or }<10 \% \text { (patients with previous } \\
\text { hypoglycemic treatment) }\end{array}$ & High risk for CV disease & $\begin{array}{l}\mathrm{CV} \text { disease or high CV risk, } \\
\mathrm{HbAlc} \geq 7.0 \% \text { and } \leq 10.5 \%\end{array}$ & $\begin{array}{l}\text { CV disease or high CV risk, } \\
\mathrm{HbAlc} \geq 7.0 \% \text { and } \leq 10.5 \%\end{array}$ \\
\hline \multicolumn{5}{|l|}{ Study population } \\
\hline Age (years) & 63.1 & & 62.4 & \\
\hline $\mathrm{HbAlc}(\%)$ & 8.1 & & 8.2 & \\
\hline CV disease (\%) & 99.4 & & 62.7 & \\
\hline End of study & April 2015 & April 2019 & April 2017 & January 2017 \\
\hline
\end{tabular}

Note: Data from the CANVAS study are combined with data from the CANVAS-R study for a pre-specified cardiovascular safety meta-analysis.

Abbreviations: CV, cardiovascular; Ml, myocardial infarction; HbAlc, glycated hemoglobin. 
showed benefits in the Prospective Pioglitazone Clinical Trial in Macrovascular Events (PROactive) study versus placebo, particularly in the main secondary end point, which consisted of the composite of all-cause mortality, non-fatal myocardial infarction and stroke (HR 0.84, 95\% CI: 0.72-0.98, $p=0.027) .{ }^{10}$ Likewise, in recently published studies with dipeptidyl peptidase 4 inhibitors, differences in cardiovascular aspects were also observed. In the Saxagliptin Assessment of Vascular Outcomes Recorded in Patients with Diabetes Mellitus (SAVOR-TIMI 53) trial, an increase was observed in the hospitalization rate for heart failure in patients treated with saxagliptin versus placebo (3.5\% versus $2.8 \%$; HR 1.27 ; 95\% CI: $1.07,1.51 ; p=0.007) .{ }^{11}$ However, these findings have not been observed in other cardiovascular safety studies with sitagliptin (Trial to Evaluate Cardiovascular Outcomes after Treatment with Sitagliptin [TECOS] $)^{12}$ or with alogliptin (EXamination of cArdiovascular outcoMes with alogliptIN versus standard of carE [EXAMINE] $).{ }^{13}$

\section{Conclusion}

The answer to the question as to whether the cardiovascular benefits observed with empagliflozin in the EMPA-REG OUTCOME study could be seen as a "class effect" will have to wait. So far, only empagliflozin has robustly demonstrated cardiovascular benefits in a specifically designed safety study following US Food and Drug Administration recommendations. Therefore, from a scientific point of view, it is advisable to await the publication of the results of currently ongoing specific cardiovascular safety studies with dapagliflozin and canagliflozin before jumping to conclusions. Furthermore, these results must not be generalized to diabetic patients with a shorter time since diagnosis and without previous cardiovascular disease or to patients with cardiovascular disease but without diabetes.

\section{Acknowledgments}

We thank BCNscience, S.L. for their assistance with medical writing. This study was funded by Boehringer Ingelheim and Eli Lilly and Company. Boehringer Ingelheim and Eli Lilly companies were involved in manuscript preparation and publication decisions.

Data supporting this commentary were obtained from cited articles. No primary or secondary dataset was created or used in this article.

\section{Author contributions}

All authors have made substantial contributions to conception, design and drafting of the manuscript or revising it critically for important intellectual content.

\section{Disclosure}

Doctor Francisco Javier Ampudia-Blasco and Doctor Ramón Gomis have carried out consulting work and/or conferences for Boehringer-Ingelheim and Lilly. Doctor Bernat Ariño is a full-time employee of BoehringerIngelheim. Doctor Irene Romera is a full-time employee of Lilly Spain. The authors report no other conflicts of interest in this work.

\section{References}

1. Zinman B, Wanner C, Lachin JM, et al. Empagliflozin, cardiovascular outcomes, and mortality in type 2 diabetes. $N$ Engl J Med. 2015;373(22):2117-2128.

2. Scheen AJ. Evaluating SGLT2 inhibitors for type 2 diabetes: pharmacokinetic and toxicological considerations. Expert Opin Drug Metab Toxicol. 2014;10(5):647-663.

3. Inzucchi SE, Zinman B, Wanner C, et al. SGLT-2 inhibitors and cardiovascular risk: proposed pathways and review of ongoing outcome trials. Diab Vasc Dis Res. 2015;12(2):90-100.

4. Grempler R, Thomas L, Eckhardt M, et al. Empagliflozin, a novel selective sodium glucose cotransporter-2 (SGLT-2) inhibitor: characterisation and comparison with other SGLT-2 inhibitors. Diabetes Obes Metab. 2012;14(1):83-90.

5. EMA. Jardiance EPAR: Public Assessment Report. 2016. Available from: http://www.ema.europa.eu/docs/en_GB/document_library/ EPAR_-_Public_assessment_report/human/002677/WC500168594. pdf. Accessed March 17, 2016.

6. EMA. Ficha técnica Forxiga. 2016. Available from: http://www.ema europa.eu/docs/es_ES/document_library/EPAR_-_Product_Information/human/002322/WC500136026.pdf. Accessed March 17, 2016.

7. EMA. Ficha técnica Invokana. 2016. Available from: http://www. ema.europa.eu/docs/es_ES/document_library/EPAR_-_Product_ Information/human/002649/WC500156456.pdf. Accessed March 17, 2016.

8. Neal B, Perkovic V, de Zeeuw D, et al. Rationale, design, and baseline characteristics of the Canagliflozin Cardiovascular Assessment Study (CANVAS) - a randomized placebo-controlled trial. Am Heart J. 2013;166(2):217-223e211.

9. Nissen SE, Wolski K. Effect of rosiglitazone on the risk of myocardial infarction and death from cardiovascular causes. $N$ Engl J Med. 2007;356(24):2457-2471.

10. Dormandy JA, Charbonnel B, Eckland DJ, et al. Secondary prevention of macrovascular events in patients with type 2 diabetes in the PROactive Study (PROspective pioglitAzone Clinical Trial In macroVascular Events): a randomised controlled trial. Lancet. 2005;366(9493):1279-1289.

11. Scirica BM, Bhatt DL, Braunwald E, et al. Saxagliptin and cardiovascular outcomes in patients with type 2 diabetes mellitus. NEngl J Med. 2013;369(14):1317-1326.

12. Green JB, Bethel MA, Armstrong PW, et al. Effect of sitagliptin on cardiovascular outcomes in type 2 diabetes. $N$ Engl J Med. 2015;373(3):232-242.

13. White WB, Cannon CP, Heller SR, et al. Alogliptin after acute coronary syndrome in patients with type 2 diabetes. $N$ Engl J Med. 2013;369(14):1327-1335.

14. AstraZeneca; Bristol-Myers Squibb; The TIMI Study Group; Hadassah Medical Organization. Multicenter trial to evaluate the effect of dapagliflozin on the incidence of cardiovascular events (DECLARETIMI58). In: ClinicalTrials.gov [Internet]. Bethesda, MD: National Library of Medicine (US); 2000 [cited 2016 Mar 2017]. Available from: https:/clinicaltrials.gov/ct2/show/NCT01730534?term=declare+timi+ 58\&rank=1. NLM identifier: NCT01730534. Accessed November 7, 2016. 
15. Janssen Research \& Development; The George Institute for Global Health (Australia). CANVAS - CANagliflozin cardioVascular Assessment Study (CANVAS). In: ClinicalTrials.gov [Internet]. Bethesda, MD: National Library of Medicine (US); 2000. [cited 2016 Mar 17]. Available from: https://clinicaltrials.gov/ct2/show/ NCT01032629?term=canvas\&rank=1. NLM identifier: NCT01032629. Accessed November 7, 2016.
16. Janssen Research \& Development; The George Institute for Global Health (Australia). A study of the effects of canagliflozin (JNJ-28431754) on renal endpoints in adult participants with type 2 diabetes mellitus (CANVAS-R). In: ClinicalTrials.gov [Internet]. Bethesda, MD: National Library of Medicine (US). 2000 [cited 201617 Mar]. Available from: https://clinicaltrials.gov/ct2/show/NCT01989754?term=canvas\&rank=5. NLM identifier: NCT01989754. Accessed November 7, 2016.

\section{Publish your work in this journal}

The International Journal of General Medicine is an international, peer-reviewed open-access journal that focuses on general and internal medicine, pathogenesis, epidemiology, diagnosis, monitoring and treatment protocols. The journal is characterized by the rapid reporting of reviews, original research and clinical studies across all disease areas.
The manuscript management system is completely online and includes a very quick and fair peer-review system, which is all easy to use. Visit $\mathrm{http}: / / \mathrm{www}$.dovepress.com/testimonials.php to read real quotes from published authors.

Submit your manuscript here: https://www.dovepress.com/international-journal-of-general-medicine-journal 